\title{
AN ARDUINO BASED EXPERIMENT TO PROVE AND TEACH MALUS' LAW
}

\author{
Esra BILAL ÖNDER ${ }^{*}$, Fatih ÖNDER ${ }^{2}$, Mehmet OĞUR $^{3}$ \\ ${ }^{1}$ Dokuz Eylül University, İzmir Vocational School, Department of Electronical Automation, İzmir, Turkey \\ ${ }^{2}$ Dokuz Eylül University, Buca Faculty of Education, Department of Physics Education, İzmir, Turkey \\ ${ }^{3}$ Bahçeşehir College, İzmir, Turkey
}

\begin{tabular}{ll}
\hline Keywords & Abstract \\
\hline Malus' Law, & The polarization of light is one of the best representations of the wave character of \\
Polarization, & light, having a wide range of applications ranging from spectroscopy to sunglasses. \\
Arduino, & The relationship between light intensity and the angle between the transmission \\
Experiment. & axis of the polarizer and the analyzer can be explained by Malus' law. In this study, \\
an experiment is presented that has been designed to prove Malus' law using simple & tools. The experiment consists of a lightproof box having an analyzer, a polarizer, \\
and an LDR, to create a dark environment, a microcontroller, the Arduino Nano, to \\
collect data from the LDR and the Polarization of Light (PoL) application developed \\
by the researchers to analyze and graph the collected data. In the experiment, a \\
graph in which the light intensity depends on the angle is drawn in real time on a \\
phone screen with an Android operating system. In the experiment, a graph of the \\
light intensity depending on the angle is drawn in real time on a phone having an \\
Android operating system. The experiment allows researchers and students to \\
directly correlate the angle change between the analyzer and polarizer axes with the \\
light intensity according to Malus' law.
\end{tabular}

\section{MALUS YASASINI KANITLAMAK VE ÖĞRETMEK AMACIYLA ARDUINO} TEMELLI BİR DENEY

\begin{tabular}{l} 
Anahtar Kelimeler \\
\hline Malus Kanunu, \\
Kutuplanma, \\
Arduino, \\
Deney.
\end{tabular}

Anahtar Kelimeler

\section{Öz}

Spektroskopiden güneş gözlüklerine kadar geniş bir uygulama yelpazesine sahip olan ışığın kutuplanması olayı, ışığın dalga karakterinin en iyi temsillerinden biridir. Işık şiddeti ile polarizör ve analizörün iletim ekseni arasındaki açı arasındaki ilişki Malus yasası kullanılarak açıklanabilir. Bu çalışmada, Malus yasasını kanıtlamak için basit araçlar kullanarak tasarlanmış bir deney sunulmaktadır. Deney, ıșık geçirmez ortam oluşturmak için kullanılan ve içerisine bir analizör, bir polarizör ve bir LDR yerleştirilmiş bir ışık geçirmez kutu, LDR'den gelen verileri toplamak için kullanılan bir mikrodenetleyici olan Arduino Nano ve toplanılan verilerin analiz edilerek grafiğe dönüștürülmesinde kullanılan, araştırmacılar tarafından geliștirilmiș, Ișığın Polarizasyonu (PoL) uygulamasından oluşur. Deneyde Android ișletim sistemine sahip bir telefon ekranında, gerçek zamanlı olarak, ışık şiddetinin açıya bağlı grafiği çizdirilmektedir. Deney, araştırmacıların ve öğrencilerin, Malus yasasına göre analizör ve polarizör eksenleri arasındaki açı değişimini, ışık şiddeti ile doğrudan ilişkilendirmelerine olanak tanımaktadır. 


\section{Introduction}

The polarization of light is an important subject that allows students to gain insight into the wave character of light. Light is an electromagnetic wave that has oscillating electric and magnetic field components. Since the electric field of light can vibrate in all possible directions, the light produced from many light sources is unpolarized. The electric field component of light should only be allowed to vibrate on a certain plane for polarization. One of the most common methods preferred for this is to use polarizing materials (Garg, Gupta and Ghosh, 2012). When the unpolarized light is incident to a polarizer, the light having the electric field component that is parallel to the transmission axis of the polarizer can pass through the polarizer. Let the amplitude of the electric field of the wave passing the polarizer be defined as $\mathrm{E}_{0}$. If a second polarizer, often referred to as the analyzer, is placed behind the first polarizer with an angle of $\varphi$ between the transmission axes, only the light having an electric field component with a magnitude of $\mathrm{E}_{0 .} \cos \varphi$ passes behind the analyzer. Since light intensity is directly proportional to the square of the electric field component, the relationship between the light intensity $\left(\mathrm{I}_{0}\right)$ incident to the polarizer and the light intensity (I) passing through the analyzer is in Equation 1.

$$
I=I_{0} \cdot \cos ^{2} \varphi
$$

This relationship connecting light intensity to the angle between the transmission axes of the polarizer and the analyzer has been set forth as Malus' law. The graphical representation of Malus' law can be shown in Figure 1. Malus' law can be easily proved by measuring the intensity of light passing through the analyzer.

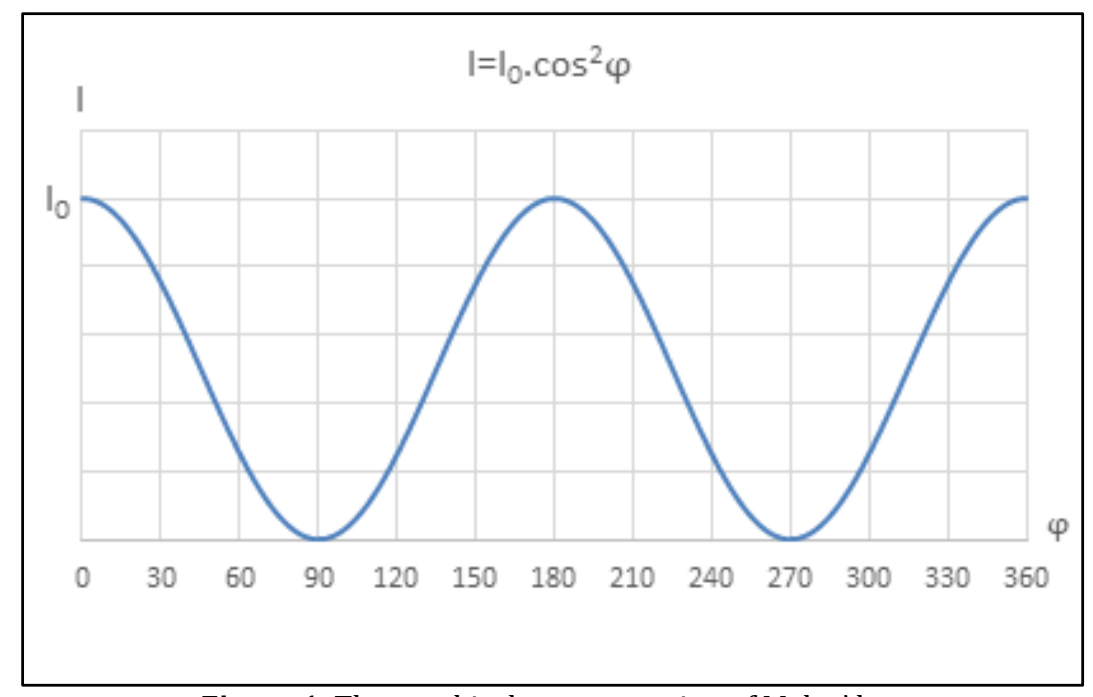

Figure 1. The graphical representation of Malus' law

In the following sections of the study, the previous studies on the teaching of Malus' law are examined and the experiment designed using Arduino in order to prove Malus' law and the results obtained from this experiment are presented. Finally, the research results were discussed in the light of suggestions for future research.

\section{Literature Survey}

Light polarization is an abstract concept in physics (Mataubenu and Langtang, 2018) and is one of the difficult issues of optics (Garg, Sharma and Dhingra, 2011, Çolak and Erol, 2020). However, learning the polarization of light is very important because of its contribution to the development of science and technology (Ishafit, Mundilarto, and Surjono, 2021). Malus' law explaining the polarization of light is an elementary area for experiment in the optical laboratory, and for students' scientific learning (Tavares and Muramatsu, 2008). Moreover, Malus' law experiment demonstrates the transverse nature of electromagnetic waves by establishing the link between optics and electromagnetism (Monteiro, Stari, Cabeza and Martí, 2017). Rosi and Onorato (2020) emphasize that students' learning difficulties are caused by the absence or insufficiency of experimental activities. Therefore, researchers are developing alternatives to the traditional Malus' law experiment using various sensors, smart phones, data collection and analysis tools and software applications.

Leung (1980) used a tungsten-halogen lamp, two lenses for collimated light, two polaroid polarizers, an interference filter, a monochramator, and a photo resistor as a light detector in the experiment designed to prove Malus' law. In this experiment, in which the angle of the polarizer was measured manually, it was emphasized that the age of the polarizers may affect the experimental data above certain wavelengths. 
In another experiment designed to prove Malus' law, data from two photoresistors of different diameters as light detector were compared with data from a selenium photocell (Tavares and Muramatsu, 2008). It was observed that photo resistors had more accurate results, and that the difference in diameters of photo resistors affected the conformity to the theoretical curve in the light intensity-angle graph.

In the Malus' law experiment designed by Kadri, Wei and Jaafar (2014), simple and inexpensive materials were used to demonstrate the light polarization quantitatively and qualitatively, and LDR was preferred as the light detector. The researchers state that the use of LDR allows students to both learn about light polarization, and put into practice their electrical and electronic knowledge in the field of optics.

Some researchers, aiming to give students more time to observe the phenomenon, experiment and interpret the results in the experiments of the linear, elliptical and circular polarization of light, have chosen to use light and rotary motion sensors and a computer-based data collection system using DataStudio software, a Science workshop interface, and accessories provided by PASCO Scientific (Amrani and Paradis, 2009; Garg et al, 2011). These researchers have underlined that the experimental setups they developed are suitable for use at the undergraduate level.

In the Malus' law experiment, the use of smartphones with various sensors for measurements can save on sensor costs. In addition, the use of smartphones has some other advantages, such as encouraging students to participate in the experimental process, making the experiment more widely accessible to students (Monteiro et al., 2017), emphasizing the link between complex equations and daily life (Çolak and Erol, 2020), and taking photos and videos of the experiment (Rosi and Onorato, 2020).

In another Malus' law experiment, using smartphones' ambient light sensor to measure the illuminance, and their orientation sensor to measure the angles, simultaneous recording of the illuminance and angle data was made with the Physics Toolbox application (Monteiro et al., 2017). Another approach involved measuring the angle manually with an adjustable anglemeter, while the Light Meter application loaded on the smartphone was used to measure the light intensity (Çolak and Erol, 2020). The data were manually recorded in the second experiment, there was a need to transfer the data to a computer and appropriate software in both experiments.

In recent years, Arduino has been used in the Malus' law experiments for various reasons. Arduino is an opensource electronics platform based on easy-to-use hardware and software (What is Arduino?, 2018) and has become a highly popular platform among hobbyists and academics in recent years (El-Abd, 2017). Arduino boards have crucial roles in fields such as smart homes, defense, industries, traffic signal control, medical, laboratories, body control, aerospace, automatic vehicle control, and these controller boards have become the most widely used in the past five years (Kaswan, Singh, and Sagar, 2020). Arduino has become popular with its ready-to-use circuit board and user-friendly IDE (Integrated Development Environment), and it allows an interdisciplinary approach to learn physics (Kotseva, Gaydarova, Angelov and Hoxha, 2019). Moreover, the use of Arduino in Physics experiments also increases students' coding knowledge (Bashir, Alhammadi, Awawdeh, and Faisal, 2019).

Arduino is easily used in the control of the experiment setup, and used in the acquisition of data, such as light intensity and angle in optical experiments. Some experiments using Arduino regarding the polarization of light and Malus' law are summarized below.

Atkin (2018) emphasizes that total internal reflection is often misrepresented in elementary books. He designed an experimental process to measure and display the intensity of reflected and transmitted light by using the Arduino.

Freitas, Cena, Alves and Goncalves (2018) designed an experimental setup that measures the rotation angle of the polarizer using a multi-turn potentiometer mechanically coupled to one of the polarizers. In this study, a potentiometer and a light sensor are connected to the Arduino panel to measure transmitted light intensity, and thus the intensity of the light is measured as a function of the rotation angle. A graphical software was used to draw the light intensity versus angle graph of the data collected from the Arduino IDE's Serial Monitor.

Mataubenu and Langtang (2018) developed a learning tool to teach the polarization of light that was effective in improving the student's scientific performance by using a photodiode sensor, the Arduino as controller or processor, and a servo motor to rotate the analyzer.

Ishafit et al (2021) developed light polarization experimental apparatus for a remote laboratory in physics education. In the experiment, a step motor controlled by Arduino was used for rotating the analyzer, and a graphical user interface developed with LabVIEW, for device control and data acquisition. According to the 
researchers, this device is also suitable for use in physics teaching in online experimentation through the installation of a webcam in a remote laboratory system (Ishafit et al, 2021).

Polarized light has many uses, ranging from astronomy to spectroscopy (Benenson, 2000). Students' understanding of the polarization of light and Malus' law, therefore, will form the basis of not only optics courses but also many other subjects in different fields of physics and engineering. The aim of this study was to design a low-cost and easily performable an Arduino based experiment that could be used in teaching the polarization of light and Malus' law. The novelty of our work is that the Polarization of Light (PoL) application we have developed allowed the light intensity and angle data collected using Arduino to be converted into graphics on an Android phone simultaneously with the data collection process.

\section{Material and Method}

\subsection{Measuring Light Intensity with an LDR}

In the experiment, an LDR (Data Sheet, 1994) was used to determine transmitted light intensity and the data from the LDR collected by using the Arduino Nano, and lastly the Polarization of Light (PoL) application, which can be installed on Android mobile devices, was used to process the data received from the Arduino.

LDRs are circuit elements whose resistance varies depending on the intensity of light. Although light intensity cannot be determined directly with LDR, associating light intensity with its resistance allows it to be used indirectly as a lux meter. In this study, resistance values between the ends of the LDR at 13 different light intensities were measured in order to establish a relationship between the light intensity and the resistance of the LDR. To this end, the LDR was connected to an ohmmeter and the light intensity was measured with a lux meter application downloaded to the mobile phone. Then, an I-R graph given in Figure 2 was drawn in Excel using the collected data.

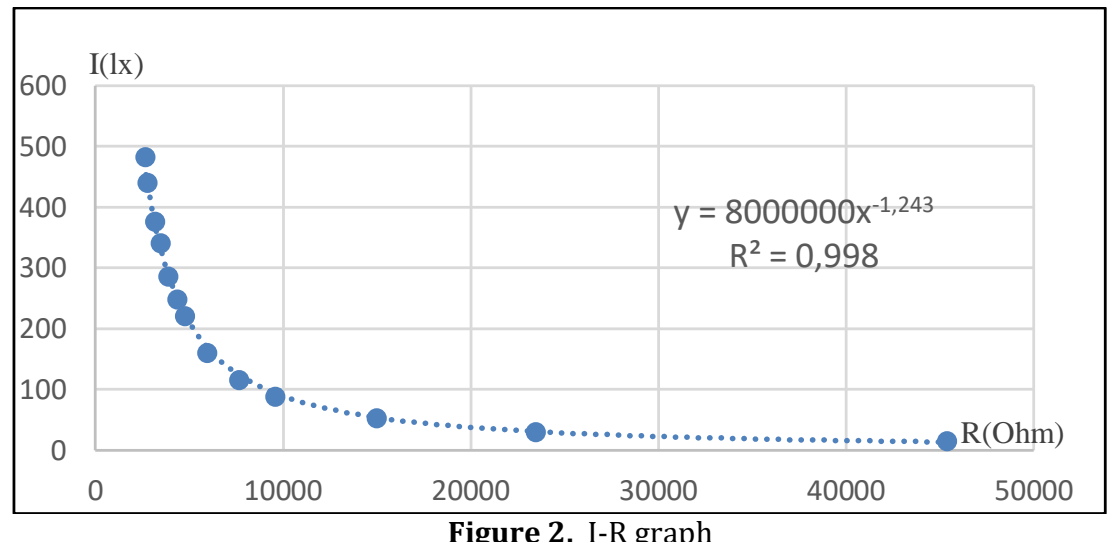

Figure 2. I-R graph

Finally, Equation 2, that gives the resistance-light intensity relation, was derived.

$$
I=8000000 \cdot R^{-1,243}(l x)
$$

By putting this equation into the PoL application, the resistance values are converted to light intensity values.

\subsection{Experimental Setup}

In this experiment, a lightproof box consisting of an analyzer, a polarizer, an LDR used to create a dark environment, the Arduino Nano was used for data collection and the Polarization of Light (PoL) application developed by the researchers was used for data processing. The lightproof box was designed using the 3D printer so that the experiment could be performed in bright environments. The box consists of two covers and a fixed body (Figure 3). 


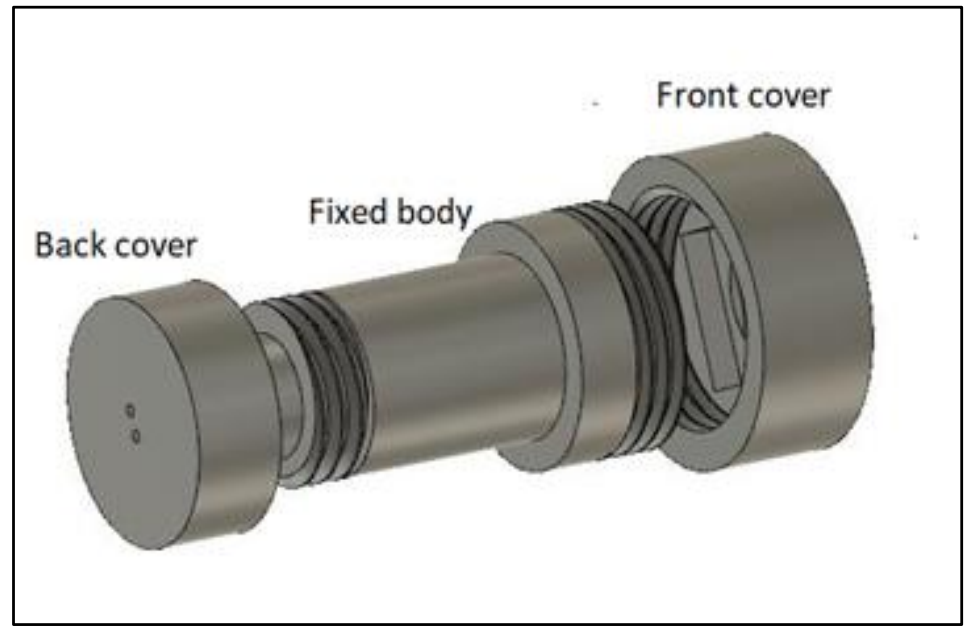

Figure 3. The lightproof box

The LDR used to determine light intensity is placed inside the back cover. In order to convert the data from the LDR to light intensity, the resistance of LDR must first be determined. Although the Arduino can measure potential differences using analog pins, it cannot read the resistance value or current directly. Therefore, a $10 \mathrm{k} \Omega$ fixed resistor was connected to the LDR in a series. The current of the LDR is then determined by calculating the current flowing through the fixed resistor since the resistor and LDR are in a series. The A0 Pin of the Arduino is connected to one end of the fixed resistance. While the difference of $5 \mathrm{~V}-\mathrm{A} 0$ yields the potential difference between the ends of the resistor, A0-GND provides the voltage of the LDR. The voltage data collected by the Arduino is then sent to the PoL application via the Bluetooth module. In the application, the current across the resistor is calculated by dividing the potential difference between the ends of the resistor by 10000. The resistance of the LDR is determined by dividing the difference A0-GND by the value of this current. The intensity of the light is also calculated using the parameters determined for LDR in Figure 2 and in Equation 2. The circuit diagram is shown in Figure 4.

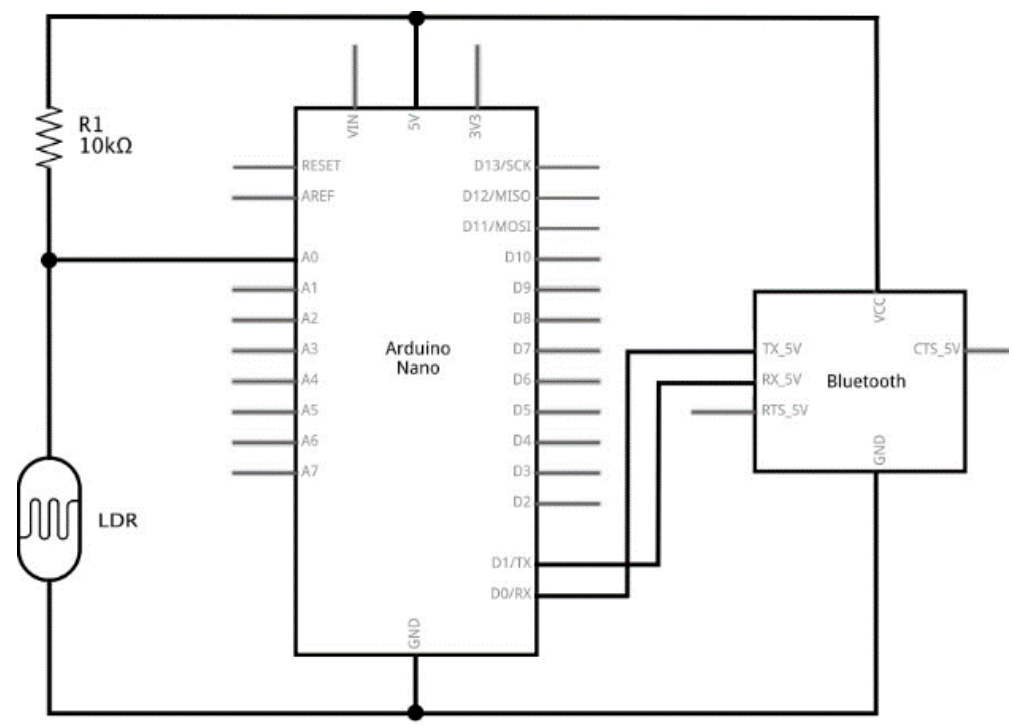

Figure 4. The circuit diagram

Polarizers were prepared by cutting out two pieces of a $2 \times 2 \mathrm{~cm}$ size from an LCD monitor. One of the polarizers was placed on the rotatable front cover with the other at the entrance of the fixed body. Thus, one of the polarizers was used as an analyzer. The values obtained by rotating the front cover are equal to the angle value between the transmission axes of the analyzer and the polarizer. The acceleration sensor of the mobile phone was used to determine the angle between the axes of the polarizer and the analyzer. The acceleration sensor cannot read angle data directly. The PoL application converts the data from the acceleration sensor of a mobile phone into angle values in degrees. A mobile phone case is screwed to the front cover. When the mobile phone is inserted into the case, it is fixed to the front cover. The experimental setup is shown in Figure 5. 


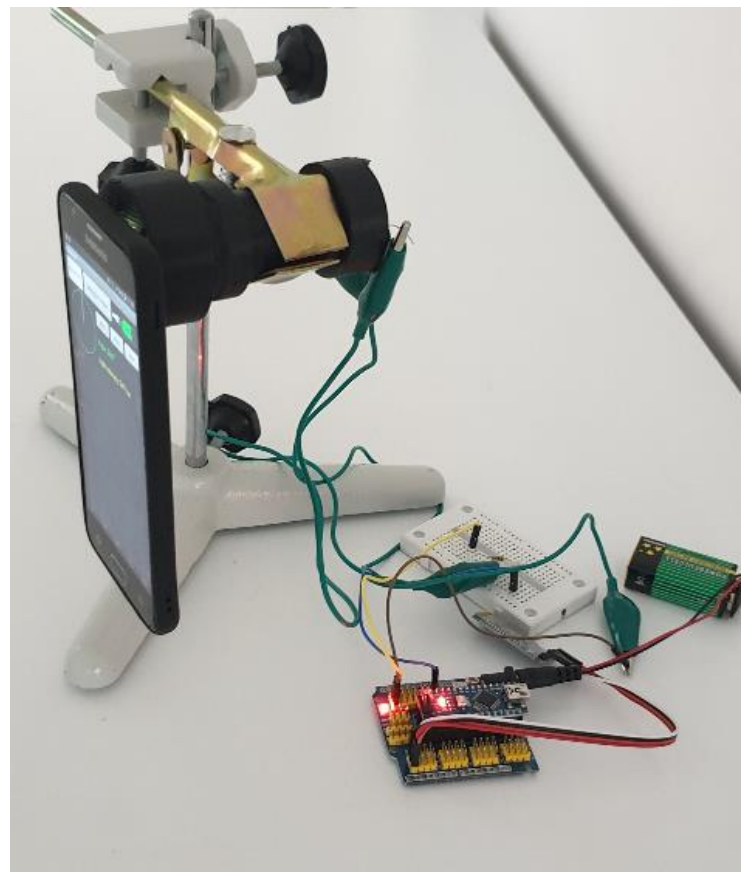

Figure 5. Experimental setup

\section{Experimental Results}

The aim of this experiment was to observe the change of light intensity on the basis of the change of angle between the analyzer and polarizer axes. For this purpose, a light intensity-angle graph was drawn based on the experimental data. Before starting the experiment, the PoL application should be downloaded and installed on the mobile phone using the QR code in Figure 6.

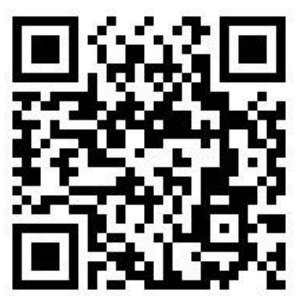

Figure 6. QR code for PoL application

The Arduino is then paired with the Bluetooth module to enable the mobile phone to collect data from the Arduino. When the application is run, the parameters screen is displayed first. If the resistance and the LDR are different from those used in this study, the necessary changes can be made on this screen. The graphic screen is displayed when the OK button is pressed.

When starting the experiment, calibration should be performed to determine the position at which the polarizer and analyzer axes are parallel to each other. To do this, the flash of the mobile phone is activated with the light button in the application. Then the cover to which the mobile phone is fixed is rotated one full turn. Thus, the application automatically determines the value at which the angle between the analyzer and polarizer axes is zero. After the calibration process is completed, the start button is pressed and the front cover and the mobile phone continues to be rotated. In the meantime, the microcontroller determines the voltage values read from the LDR and the resistor and sends these values to the mobile phone simultaneously. After the PoL application calculates the light intensity and the angle values, these values are sent to an I- $\varphi$ graphic at every $100 \mathrm{~ms}$ and marked as a point on the graph. The flowchart of the experiment is given in Figure 7. 


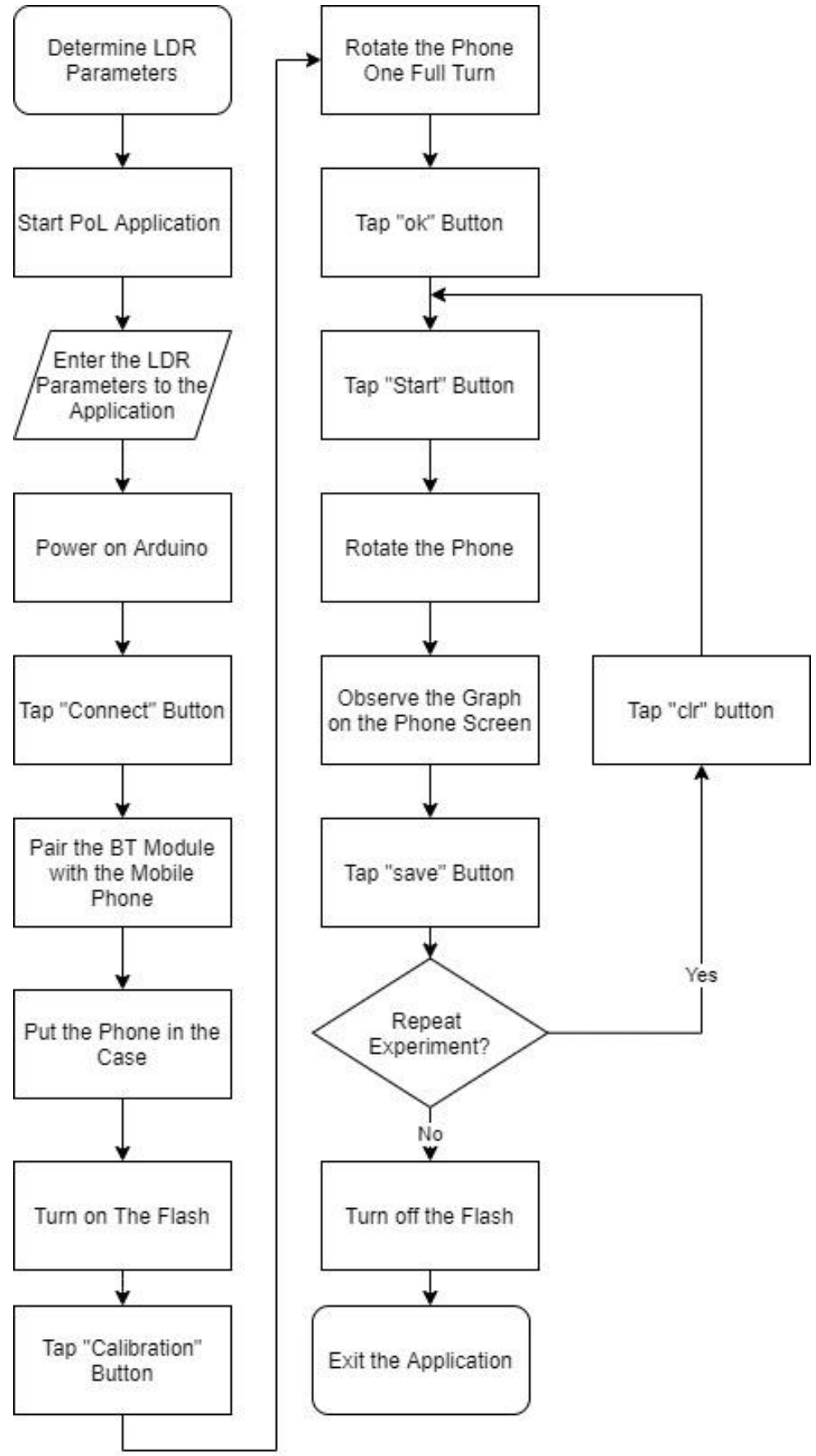

Figure 7. Flowchart of the Experiment

To change the frequency of the points seen in this graph, all that has to be done is to change the number value in the delay $(0$ code in the code index shown in Figure 8.

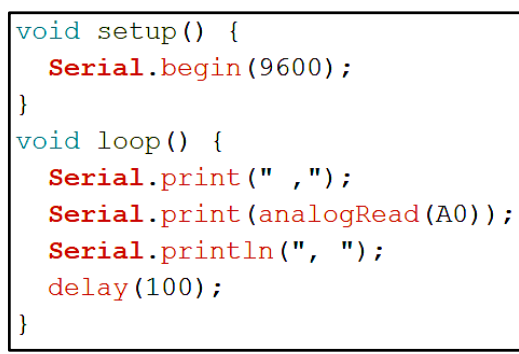

Figure 8. The Arduino code 
The experiment was conducted by taking data every $100 \mathrm{~ms}$ and $400 \mathrm{~ms}$. Screenshots of the obtained graphics are presented in Figure 9 (a) and (b), respectively. It is seen that the graphs in Figure 9 drawn with the experimental data are the same as the Malus' law graph in Figure 1.

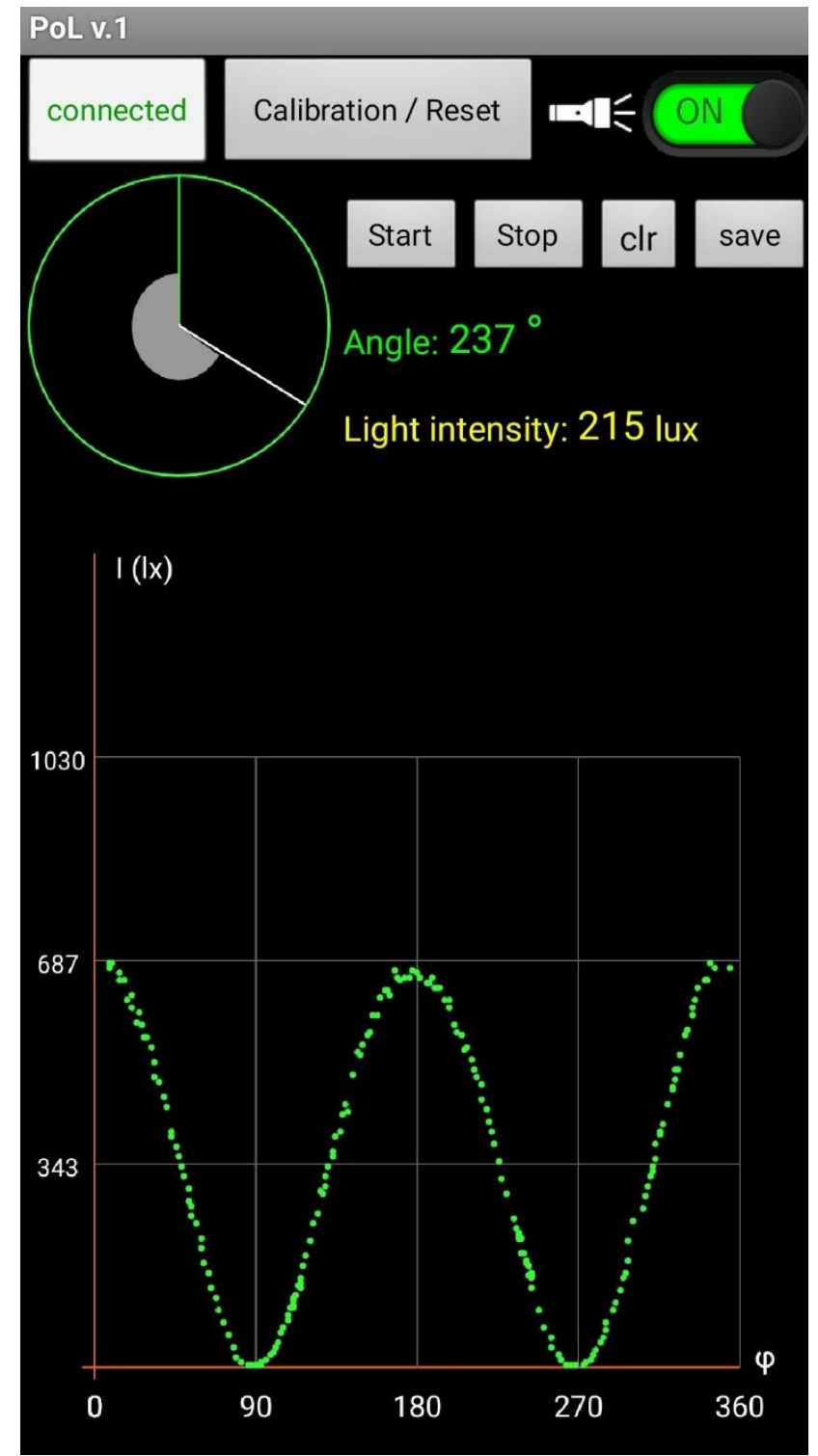

(a)

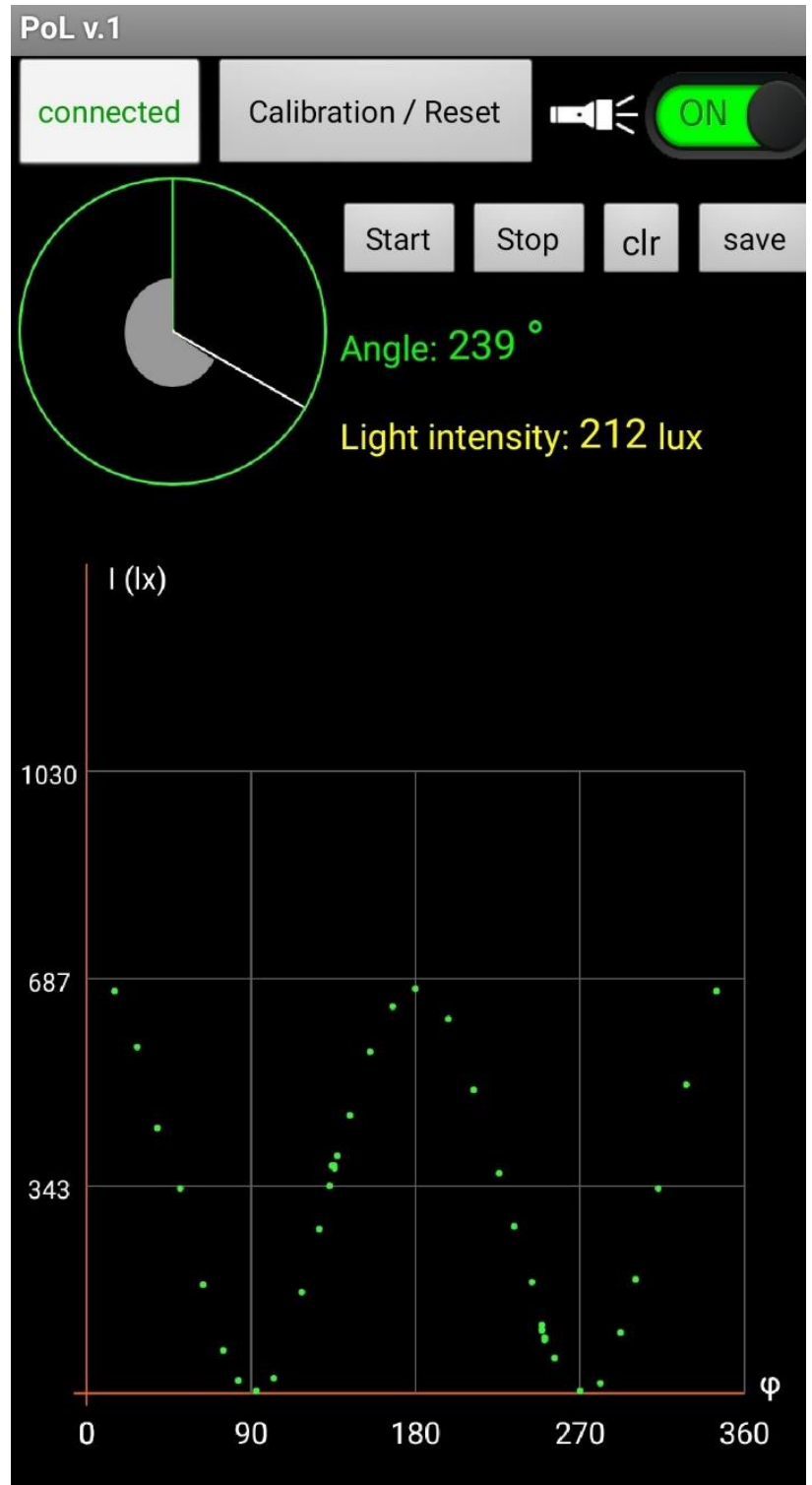

(b)

Figure 9. I- $\varphi$ graph displayed on mobile phone by collecting data at every (a) $100 \mathrm{~ms}$ and (b) $400 \mathrm{~ms}$

\section{Conclusions and Discussion}

A light polarization experiment proved Malus' law can be performed with the experimental setup using simple and cheap materials. In the experiment, the light intensity-angle graph can be observed simultaneously with the change of angle between the analyzer and polarizer axes. The graph obtained as a result of the analysis of the experimental data, shown in Figure 9, is compatible with the graphical representation of Malus' law, shown in Figure 1.

It can be said that the experimental setup has three important advantages over classical experimental setups. The first of these is cost. Analyzers and polarizers can be obtained from recycled computer monitors or unused polarized sunglass lenses. It is possible to obtain dozens of polarizers and analyzers from a standard obsolete laptop monitor. LDR, which is used to determine the light intensity, is a very inexpensive resistor that can be obtained from every electronic dealer. Arduino Nano, which is used to collect data, is one of the most accessible and cheap microcontroller in the market. The application used in data processing and graphing is free of charge. High costs are the biggest obstacle to having experimental setups that can collect such sensitive data in schools. This cost reduction is important as it will contribute to more students achieving this type of experimental setup. Low cost Physics experiments give students the chance to work in a way that suits their cognitive style, to try it on their own, to adapt their own hypotheses about the problems, and to develop their own problem-solving methods 
(Josey, Alvi, Kattayat and Asha, 2018). The importance of using low-cost materials is emphasized as well in other studies related to the Malus' law experiment (Çolak and Erol, 2020; Ishafit et al, 2021; Kadri et al, 2014; Kostan et al, 2018; Monteiro et al, 2017; Rosi and Onorato, 2020; Tavares and Muramatsu, 2008).

The second advantage of the experimental setup is that it allows data collection without the need for a dark environment. Classical experimental setups used in proving Malus' law require dark laboratories that do not receive light. Any light that may come from outside the light source used affects the experimental results. Mataubenu and Langtang (2018) recommend that the Light Polarization Learning Tool Based on Arduino, which they developed, be tested in a dark room in order not to disturb the light source. In our experimental setup, the LDR measuring the light intensity was placed in a closed box and the light source of the mobile phone was positioned right in front of the polarizer. This prevents light outside of the light source we use coming to the LDR. The experiment can be done even in daylight. In this experiment, the lightproof box was made using a threedimensional printer. If this type of printer is not available, the box can also be made using any cardboard or metal box. It will be sufficient to fix the analyzer in front of the LDR, place the polarizer in a hole to be opened in the lid of the box. This structure of the experimental setup makes it suitable for use both in the laboratory and in the classroom. According to Tavares and Muramatsu (2008), when students assemble, calibrate and use LDRs, they both learn significant laboratory techniques and develop patience and decisiveness to achieve accurate results.

The third advantage of the experimental setup is that it allows real-time data collection and graphing. According to Amrani and Paradis (2009), a real-time display of the experimental data simplifies the analysis and interpretation of the results. In a classical experimental setup, students collect data and draw the graph at the end of the experiment. In this setup, since the graphic is drawn simultaneously with the data collection process, students can interpret the change of light intensity according to the position of the polarizer throughout the experiment. Since the experimental setup receives data at every $100 \mathrm{~ms}$, it allows more data to be collected in less time than conventional experimental setups. This enables the creation of a graph that consists of frequent points that can be interpreted more easily. The Polarization (PoL) application we have developed enables the light intensity and angle data collected using Arduino to be converted into graphics on an Android phone screen simultaneously with the data collection process. In this way, there is no need to transfer experimental data to a computer for graphics. In addition, conducting the experiment in this way allows students and teachers to both save time and use less tools. In other studies, where the Malus' law experiment was carried out, computers were used for data analysis and drawing graphics (Amrani and Paradis, 2009; Çolak and Erol, 2020; Garg et al, 2011; Kadri et al, 2014; Monteiro et al, 2017; Tavares and Muramatsu, 2008). In addition, these graphics created with the PoL application can be saved to their smart phones by students and shared with others. This provides students with an effective inquiry environment. The automation of data collection and analysis in experiments is therefore important in allowing for students sufficient time to observe, apply variations, and interpret results (Garg et al, 2011). The fact that the graph can be drawn simultaneously with the data collection process may also make it possible to use this experiment as supporting material in course presentations.

In the following studies, the effect of the designed experimental setup on students' attitudes and achievements towards the physics can be examined.

\section{Conflict of Interest}

No conflict of interest was declared by the authors.

\section{References}

Amrani, D., Paradis, P., 2009. Malus's law of light polarization using a computer-based laboratory. Latin American Journal of Physics Education, 3(2), 229-231.

Atkin, K., 2018. An Arduino-based experiment designed to clarify the transition to total internal reflection. Physics Education, $53,025003$.

Bashir, A., Alhammadi, M., Awawdeh M., Faisal, T., 2019. Effectiveness of using Arduino platform for the hybrid engineering education learning model. Advances in Science and Engineering Technology International Conferences (ASET), pp. 1-6. doi:10.1109/ICASET.2019.8714438.

Benenson, R.E., 2000. Light polarization experiments with a diode laser pointer. Physics Teacher, 38, 44-46.

Çolak, İ. Ö., Erol, M. 2020. Realization of polarization and Malus's law using the smartphones. Jurnal Pendidikan Fisika Indonesia, 16(1), 9-13.

Data Sheet, Light Rependent Resistors. (1997, March). https://components101.com/asset/sites/default/files/component_datasheet/LDR\%20Datasheet.pdf. Date accessed April $04,2021$.

El-Abd, M., 2017. A review of embedded systems education in the Arduino age: lessons learned and future directions. International Journal of Engineering Pedagogy, 7(2), 79-93. 
Freitas, W.P.S., Cena, C.R., Alves, D.C.B., Goncalves, A.M.P., 2018. Arduino-based experiment demonstrating Malus's Law. Physics Education, 53, 035034

Garg, A., Sharma, R., Dhingra, V., 2011. Polarization studies in a computer based laboratory. Latin American Journal of Physics Education, 5(1), 114-118.

Garg, S., Gupta, S., Ghosh, C. K., 2012. Wave Optics. New Delhi: PHI Learning. p 54.

Ishafit, Mundilarto, Surjono, H.D., (2021). Development of light polarization experimental apparatus for remote laboratory in physics education. Physics Education, 56, 015008.

Josey, S., Alvi, P.A., Kattayat, S., Asha, J. V., 2018. Effectiveness of 'low cost experiments' in assimilating fundamentals of physics. International Journal of Mechanical Engineering and Technology, 9(11), 860-866.

Kadri, S., Wei, D. C. B., Jaafar, R., 2014. Student activity: verification on Malus's law of polarization at low cost. Proc. SPIE 9289 , 12th Education and Training in Optics and Photonics Conference, 928992A, 1-9. https://doi.org/10.1117/12.2070727

Kaswan, K. S., Singh, S. P., Sagar, S., 2020. Role of Arduino in real world applications. International Journal of Scientific \& Technology Research, 9(1), 1113-1116.

Kotseva, I., Gaydarova, M., Angelov, K., Hoxha, F., 2019. Physics experiments and demonstrations based on Arduino. AIP Conference Proceedings 2075, 180020. https://doi.org/10.1063/1.5091417

Leung, A. F., 1980. The law of Malus using polaroid polarizers. Physics Teacher, 18, 612-614

Mataubenu, K.D.F., Langtang, D., 2018. Development of light polarization learning tool based on Arduino and scientific performance. International Journal of Science and Research, 7(12), 156-160.

Monteiro, M., Stari, C., Cabeza, C., Martí, A.C., 2017. The polarization of light and Malus' law using smartphones. Physics Teacher, $55,264-266$

Rosi, T., Onorato, P., 2020. Video analysis-based experiments regarding Malus' law. Physics Education, 55, 045011.

Tavares, A.D., Muramatsu, M., 2008. Some simple experiments in optics using a photo-resistor. International Journal on Handson Science, 1(2), 84-88.

What is Arduino? (2018, February 05). https://www.arduino.cc/en/Guide/Introduction. Date accessed April 04, 2021. 